Kanosvamhira, T.P. (2018). The organisation of urban agriculture in Cape Town, South Africa: A social capital perspective.

Development Southern Africa, 2018.

http://dx.doi.org/10.1080/0376835X.2018.1456910

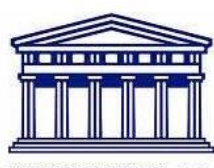

UNIVERSITY of the WESTERN CAPE

\title{
The organisation of urban agriculture in Cape Town, South Africa: A social capital perspective
}

\author{
Tinashe Paul Kanosvamhira
}

\begin{abstract}
This article explores urban agriculture in Cape Town and its organisational forms. Based on a literature review of peerreviewed articles and grey literature, it examines the state of linkages among urban farmers and various supporting organisations of urban agriculture. Moreover, it examines the coordination of activities among key supporting organisations. By analysing the roles of state and non-state actors and linkages, the article discusses implications for the development of urban agriculture. This article suggests that a lack of effective coordination of initiatives among supporting actors presents a significant pitfall in the development of urban agriculture. Furthermore, the failure of farmers to self-organise is identified as equally detrimental. Therefore, it calls for improved synergies between state and non-state actors involved to ensure that the gains of urban agriculture are enhanced.
\end{abstract}

\section{Introduction}

Cape Town has a long history of supporting urban agriculture within its borders (Rogerson, 2010), in fact, it is the only South African city with an urban agriculture policy (Olivier \& Heinecken, 2017). Olivier \& Heinecken (2017) argue that Cape Town has the most diversified urban agriculture sector, with support from both nongovernmental organisations (NGOs) and the government. Visser (2006) holds that increasing unemployment levels and failure of the economic sector to absorb the unemployed encouraged the city to employ urban agriculture as an intervention strategy to generate jobs and counter poverty. According to Battersby et al. (2014), there are at least 100 NGOs supporting the practice across the city. Notwithstanding, the economic benefits of urban agriculture in Cape Town remain modest (Haysom et al., 2017). One of the factors responsible for this has been identified as the limited coordination amongst supporting actors (Haysom \& Battersby, 2016), but from a broader perspective equally important is the organisation of urban farmers (Voleníková \& Opršal, 2016). Collective organisation among urban farmers has been recognised as a necessary strategy to ensure access to resources from supporting organisations (Schmidt et al, 2015). Moreover, Voleníková \& Opršal (2016) suggest that urban farmer organisation facilitates the lobbying for desired developmental change. In other words, a more unified voice from the urban farmers aids in lobbying for policy development. Consequently, the success of urban agriculture does not lie only in the ubiquity of support but equally 
significant is the organisation of the urban farmers in accessing resources and influencing favourable change. Furthermore, the linkages between the supporting actors are crucial as they potentially enhance the impact of urban agriculture initiatives.

Missing in the South African discourse is an exploration of the coordination between urban farmers and supporting organisations. Moreover, available literature fails to interrogate the factors which facilitate the networking of urban farmers. As a result, this dearth of information affects policymakers in the formulation of inclusive urban agriculture initiatives.

Against this background, this article attempts to examine the organisation of urban agriculture in Cape Town. As such, a possible future scenario for the practice is discussed. To this end, a review of peer-reviewed articles and grey literature on urban agriculture in Cape Town was conducted. Furthermore, the adoption of the social capital lens to explore these complex relationships among the supporting actors and the urban farmer in Cape Town ensured the possibility of identifying gaps that need further exploration. This discussion also seeks to advance a theoretical perspective of social capital in developmental initiatives. This article unfolds through three sections. Firstly, the theoretical lens for the discussion is presented, followed by a review of the literature on the organisation of urban agriculture. Finally, conclusions are drawn in the last section providing possible recommendations for academia and policymakers.

\section{The link between social capital, social development and urban agriculture}

The social capital theory was employed as the analytical framework for this discussion as it enables one to appreciate linkages between individuals, groups and institutions. The concept of social capital is characterised by various definitions across various disciplines such as economics, sociology, business, education, anthropology and political science (Megyesi et al., 2015). However, Liou \& Chang (2008:99) suggest that despite the lack of a unanimous definition of social capital, there is a general consensus that 'social networks are assets'. This study adopted the definition by Martin et al. (2000:10) which states that social capital is the social relationships in which individuals and communities are involved, including networks, membership of groups and levels of trust and reciprocity'. This definition was adopted as it tries to capture the essence of the various definitions provided by the main promulgators of the concept. Megyesi et al. (2015) state that the primary positive impacts of social capital are the reduction in transaction costs through facilitating collective action.

According to Putman (2000), social capital exists in three different forms, namely bonding, bridging and linking. In the context of urban agriculture, these forms of social capital have different impacts on the resources available to urban farmers. Woolcock (2001) defines bonding as the horizontal relationships occurring in a homogeneous group. In this regard, bonding brings together individuals who are already acquainted. 
This facilitates the first line of networking amongst urban farmers in the same locality. Through this network, urban farmers interact with each other.

Bridging social capital attempts to link members of distant groups to enable the mobilisation of external resources (Woolcock, 2001), where people who do not know each other may be connected to one another (Nieman, 2006). Such people include distant friends, associates and colleagues. Here cooperation has the potential to generate trust between the individuals, fostering collective action. Saegert et al. (2001) identify institutions such as churches as significant in increasing bridging capital in a community. This is because such institutions present a platform were members of the society can interact despite their various backgrounds. The authors believe that such platforms enable the sharing of ideas and resource mobilisation. Furthermore, Olivier \& Heinecken (2017) note that, unlike bonding, bridging capital is a more effective means of information dissemination. Finally, Szreter \& Woolcock (2004:655) define linking as the linkages 'between people who are interacting across explicit, formal or institutionalized power or authority gradients in society'. Nieman (2006) notes that the relationships generated through this form of social capital extend beyond the community, encompassing institutions outside the community borders. Woolcock (2001) argues that linking is a necessity in ensuring that the community can access additional resources such as information and training. This implies that linking is applicable to communities where the resources required may not necessarily be found within the community borders, hence the need to obtain them elsewhere. According to Nieman (2006), it takes deliberate effort from the public institutions in building this form of social capital. Nieman (2006) argues that effective coordination is required to ensure that relationships are to be formed with the local communities. In other words, the responsibility, in part, lies with the institutions to ensure that underdevelopment is addressed in the communities.

In a South African context, Nieman (2006) argues that identifying and utilising existing social capital should be prioritised by the public institutions and welfare organisations when implementing development programmes. This is because the concept of social capital is instrumental for practitioners when rolling out community development initiatives. Therefore, there is a need to exploit and build upon the already existing social capital in the area to ensure the success of the projects. Moreover, Nieman (2006:166) identifies participation, networking and training 'as good-practice criteria' for successful development initiatives. In the same way, Malan (2015) argues that the social capital theory is invaluable in the context of urban agriculture because it enables the links between urban farmers and organisations to be identified. The author identifies this as the first step supporting organisations should analyse and tap into before providing support for urban farmers.

The City of Cape Town (CoC) views 'urban agriculture as a way to address some of the economic and social imbalances' in the post-colonial era (Battersby \& Marshak, 2013:457). Likewise, NGOs in the city have a long history of using urban agriculture as a tool to 
counter poverty in urban communities (Karaan \& Mohamed, 1998; Tembo \& Louw, 2013; Olivier \& Heinecken, 2017). In this regard, urban agriculture can be considered a community development initiative employed by these supporting organisations. Drawing from the argument by Nieman (2006), the social capital concept must be interwoven in the initiatives pursued by such organisations if urban agriculture is to achieve some level of success.

\section{The organisation of urban agriculture in Cape Town 3.1. State actors}

Battersby et al. (2014), based on a report on urban food systems in Cape Town, identify the municipal government and the Western Cape Department of Agriculture (DOA) as significant state actors in urban agriculture within the city. As already mentioned, the city endorsed urban agriculture through the Urban Agriculture Policy in 2007. The policy seeks to facilitate an integrated and holistic approach for the effective and meaningful development of urban agriculture in the City of Cape Town ... and to create an enabling environment wherein public, private and civil society agents can work collectively to create more real and sustainable opportunities for local area economic development. (CoCT, 2007:2)

Additionally, the policy follows a dual approach of attempting to improve household food security and the generation of income for disadvantaged households (CoCT, 2007). Battersby et al. (2015) state that most recently the city Strategic Development Plan for the Development of Urban Agriculture in the City of Cape Town (2013/14-2015/16) developed seven key areas for translating the urban agriculture policy into action. However, it is important to underscore that this 'new policy' has not been made public to date, which raises more questions than answers with regard to the future of the institutional landscape of urban agriculture in Cape Town. Further, the City passed the Food Gardens Policy to tackle food insecurity through food gardens (Battersby et al., 2015). According to Haysom et al. (2017:39) the Food Gardens Policy 'has effectively eclipsed the Urban Agriculture Policy'. As a result, the majority of the work done by the City of Cape Town urban agriculture unit has been effectively curtailed (Haysom et al., 2017).

While the city facilitates the engagement of various stakeholders and officially recognises urban agriculture within the city borders (Olivier \& Heinecken, 2017), it has been criticised on a number of grounds. Firstly, Battersby \& Marshak (2013) carried out a study which identified that the aims of the Urban Agriculture Policy were not inclusive of the aims of the urban farmers. Their findings indicated that while the policy framed urban agriculture in economic terms, urban gardeners framed it along with social benefits (Battersby \& Marshak, 2013). Tembo \& Louw (2013) hold that once project conceptualisation differs between the project implementer and beneficiaries then problems arise with respect to implementation and sustainability. Consequently, this may be partially responsible for the challenges experienced in the sector. Secondly, implementation is found lacking due to the urban agriculture unit being under- 
resourced (Minné, 2013) and failure to integrate the practice into the spatial framework of the city (Rabkin, 2013). Apart from the city, the Provincial DOA plays a crucial role in supporting urban agriculture (Swanepoel et al., 2017).

According to Battersby et al. (2014), the Western Cape Department of Agriculture has supported 114 community gardens in the metropolis since 2008. The Provincial DOA provides support in the form of agricultural starter packs for school, community and household gardens (Swanepoel et al., 2017). Therefore, despite Thornton's (2008) assertion that poorer urban cultivators in South Africa fail to access government assistance, in this instance Cape Town is an exception (Olivier \& Heinecken, 2017). Nonetheless, Kirkland(2008:114) notes that the Department of Agriculture only provides assistance 'when projects are starting up', therefore there is limited monitoring of projects (Battersby et al.,2014). This obviously creates problems of project sustainability.

Secondly, Haysom \& Battersby (2016) in their review paper 'Urban agriculture the answer to Africa's food crisis?' postulate that the success of the urban agriculture is hindered by a lack of coordination between the state and non-state actors. They note that NGOs do have viable urban agriculture projects and the local government should work closely with them so as to improve the viability of state projects. There are in excess of 100 non-governmental organisations supporting urban agriculture in the city (Olivier \& Heinecken, 2017), therefore this presents an opportunity for the municipal government to synergise with such organisations so as to improve the coordination of its activities and extend the benefits of urban agriculture initiatives.

Moreover, Haysom \& Battersby (2016) maintain that the situation is exacerbated by lack of monitoring and evaluation of government initiatives. They state that monitoring by government is relatively weak and this means lessons are not being learned from failing programmes. For example, Battersby et al. (2014) noted that during a survey of community gardens in Cape Flats they could not obtain enough data on selected gardens due to the lack of record-keeping (monitoring) by the Provincial DOA. They recommend the government to improve the monitoring of projects so as to ensure that they are ultimately a success. Consequently, due to limited government involvement in the actual groundwork (monitoring and training) NGOs play a crucial role in supporting urban farmer groups in Cape Town (Olivier, 2015:56).

\subsection{Non-state actors}

Olivier \& Heinecken (2017) note that NGOs have been the main instigators of the development of urban agricultural activities in Cape Town. Battersby et al. (2014) observe that some of the biggest organisations include Abalimi Bezekhaya and Soil for Life. For instance, Abalimi Bezekhaya (AB) has been in operation since 1982 (Karaan \& Mohamed, 1998). The organisation currently supports 4558 members (Olivier \& Heinecken, 2017), from the poor communities of Khayelitsha and Nyanga. Karaan \& 
Mohamed (1998) note that through donor funds, the organisation is able to subsidise inputs and improve infrastructure and market opportunities for urban farmers.

Similarly, Soil for Life (SFL) is another organisation that has improved urban agriculture activities throughout Cape Town. Soil for Life has an official memorandum of understanding with the City of Cape Town (Battersby et al., 2014) and currently has 1930 members (Olivier \& Heinecken, 2017). The relationship between Soil for Life and the City of Cape Town is an example of how the Urban Agriculture Policy has ensured improved relationships between state actors and non-state actors. Van Der Merwe (2003) observes that the organisation initially supported both home gardens and large community projects. However, the organisation has stopped initiating community gardening projects due to a lack of sustenance (Battersby \& Marshak, 2013), suggesting that there is limited social capital within communities. The home garden project supports home production in low-income households. This project has allowed a number of low-income households to access training and inputs enabling them to engage in home garden projects. In fact, the organisation reports that 3930 home gardeners residing in low-income areas have been trained between 2009 and 2016 (Soil for Life, 2017).

The significance of such NGOs is detailed by Olivier \& Heinecken (2017). In their study carried out across urban farmers in Cape Town, they observed that NGOs play vital functions in improving urban agriculture activities in the city. Firstly, they note that such organisations are able to connect cultivators to the private-sector market, thereby creating a source of income: for example, the Harvest of Hope project implemented by Abalimi Bezekhaya, which allows community gardens to supply products to consumers through the selling of fresh vegetable boxes. Kirkland (2008:118) reports that individually urban farmers would not be able to access markets without NGOs assistance. Secondly, the study revealed that NGOs enable farmers to access the public institutions. In this regard, the organisations are able to assist in facilitating land access from the state, which is a form of social capital linking.

Citing examples from Abalimi Bezekhaya and Soil for Life, it is clear that NGOs provide important links between urban farmer groups and stakeholders such as the government and the private sector (markets and donors). Olivier \& Heinecken (2017) conclude that urban farmers would not be able to access such opportunities without the presence of NGOs. Consequently, they need support from the government and private sector as they do also face challenges. For example, the interim chief executive officer of Abalimi Bezekhaya noted that finance and the diversity of beneficiaries in terms of background and politics were their greatest challenges (Barr, 2017). Hence research institutions and funders can play a substantial role in this respect. For instance, communities differ with respect to struggles and culture, hence research is fundamental to aid NGOs in formulating tailored responses for the different farmers. Moreover, coordination of NGOs is not well documented in the literature. Hence these areas present a gap in the literature which needs to be addressed. 


\subsection{Urban farmer organisation and obstacles to self-organisation}

It is important to underscore the fact that several multi-stakeholder forums have been initiated in the past in an attempt to improve urban farmer organisations in Cape Town. For instance, the events leading up to the creation of the Urban Agriculture Policy of Cape Town were characterised by stakeholder participation (Visser, 2006; Dubbeling et al., 2010). Moreover, the City of Cape Town has continuously engaged in various projects to foster the exchange of information on multi-stakeholder participation in urban agriculture. A case in point is its participation in Urban Agriculture and Food Security: Africa-Toronto Exchange in 2010 ('Urban Agriculture', 2010). The overall objective of this exchange was to facilitate a learning experience from established multi-stakeholder organisations such as the Nairobi and Environs Food Security, Agriculture, and Livestock Forum (NEFSALF). According to Lee-Smith (2011), the NEFSALF, consisting of NGOs, government, urban farmers and the market sector, has served as a dialogue platform for all the actors involved to address urban agriculture and food security in Nairobi, Kenya. Furthermore, it has encouraged the sprouting of self-organised urban farmer groups at local levels in an attempt to access the benefits offered by the forum. Therefore, the exchange programme provided an opportunity for Cape Town to learn from Nairobi's experience. More recently, the Urban Agriculture for Food Security and Income Generation in South Africa and Mozambique (UFISAMO) project has attempted to conduct stakeholder dialogues and scenario workshops across Cape Town (Hoffmann et al., 2016) in an attempt to rejuvenate multi-stakeholder dialogue. The results of these initiatives are yet to be seen as the project is ongoing.

In essence, the cited examples demonstrate that there have been attempts to improve the state of urban agriculture through stakeholder dialogues. However, the challenge is the organisation of the urban farmers themselves who are in fact the subject of these discussions. Accordingly, stakeholders may have to understand some of the challenges urban farmers face in self-organising and use these as a starting point to offer assistance. It is important to note that there is a dearth of studies which focus on the organisation of urban agriculture in Africa (Schmidt et al., 2015). Similarly, the same situation exists in Cape Town. Nonetheless, a few obstacles hindering selforganisation can be drawn from available literature.

First, land tenure security presents a distinctive problem 'for it determines the extent of investment and self-help put into property' (Rogerson, 2010:376). Unfortunately, insecurity of tenure has resonance across the country, including Cape Town (Karaan \& Mohamed, 1998). The lack of land tenure results in the prevalence of insecure and informal land tenure arrangements. Regarding urban farmers' self-organisation, this presents a notable challenge as production practices are short-term and characterised by constant searching for new land when the current land tenure ends or is violated. As such, urban farmers are never in a single place long enough to form relations with each other and possibly establish a functional urban farmer group. This affects not only group gardeners but home gardeners who are tenants on the property. 
Second, Schmidt et al. (2015) argue that urban farmers' spatial fragmentation presents a significant hindrance to self-organisation particularly at a local level. Urban farmers in Cape Town are spatially fragmented across the urban area (Olivier \& Heinecken, 2017); hence the opportunity to interact frequently is reduced as they work on individual plots, which stifles attempts to self-organise. In cases where farmers are able to meet, for instance, in the case of community gardens, issues of effectiveness and efficiency affect group sustainability.

Third, in cases were urban farmers are able to organise Wilbers et al. (2007) hold that effectiveness and efficiency affect the sustainability of the group. In a study of community gardens across Khayelitsha Sombalo (2003) noted that urban farmer groups were prone to disintegration and internal conflicts. Reuther \& Dewar (2006) argue that group members of the Siyazama Community Allocation Garden Association (SCAGA) easily left the garden if they found alternative employment. Reuther \& Dewar (2006) cite this as a serious impediment to the sustainability of the groups. Battersby \& Marshak (2013) observe that a local non-governmental organisation has stopped trying to establish group garden projects because gardeners did not take ownership, which obviously affected its sustainability. Since community gardening is dependent on 'collective input'(Battersby \& Marshak, 2013:454) high attrition rates among groups directly translate to low production levels and wastage of efforts and resources (Tembo \& Louw, 2013:234).

Finally, the diversity of the urban farmers with respect to socio-economic status makes it unlikely to have farmers unite and share the same interest. Similarly, in Cape Town urban farmers migrate from different places and as far as Zimbabwe (Olivier \& Heinecken, 2017). Additionally, the diverse backgrounds of urban farmers engaging in urban agriculture in Cape Town (Barr, 2017) translate to various needs, making it difficult for urban farmers to unite under a common objective. This is best exemplified by the Siyazama Community Allocation Garden Association, which almost collapsed due to varying agendas among the garden participants (Small, 2007).

Nonetheless, various urban farmers have been able to unite across sub-Saharan Africa with relative success. For instance, Schmidt et al. (2015) observe that urban farmers in Dar es Salaam and Moshi (Tanzania) have united despite socio-economic status. Although the urban farmer groups are presented with challenges they were able to tackle them collectively. Similarly, Maconachie et al. (2012) report a prevalence of urban farmer associations in Free Town (Sierra Leone). Based on a survey they observed that the proliferation of urban associations in the city was a strategy employed by urban farmers to overcome obstacles, primarily the issue of land insecurity. Moreover, they were able to access support from NGOs and government in the form of training and subsidised inputs.

Essentially, this indicates that despite the various hindrances facing urban farmers across Cape Town they possess the capacity to unite. In fact, a good example is the Philippi Horticultural Area (PHA) Food and Farming Campaign, which was formed by small-scale 
farmers to try and counter developmental initiatives by the private sector (van der Merwe, 2016). This case provides a suitable example of peri-urban farmers uniting under a single voice for a common cause. Although it was a reactive response, learning experiences can be drawn from the PHA Food and Farming Campaign. Perhaps what is required is a more proactive approach from the urban farmers. In this respect, stakeholders may need to appreciate the status of urban farmers as the first step towards understanding how best they can be assisted. This calls for more research surrounding urban agriculture organisation to ensure informed decision-making. In fact, Frayne et al. (2014) argue that contextual elements are crucial in determining responses to urban agriculture. For this reason, case-study inquiries may be crucial in understanding the situation across different urban farming communities in Cape Town before response measures can be crafted.

\section{Conclusion}

This article endeavoured to explore the organisation of urban agriculture in Cape Town through a social capital lens by reviewing the roles of state and non-state actors in supporting urban farmers in the metropolis. As already noted in the discussion, various issues emerge from the literature. Primarily, it is clear that despite a plethora of supporting organisations across the landscape there is limited coordination amongst them. This lack of synergy has been attributed to possibly varying agendas amongst the actors. Unfortunately, such a scenario results in the unnecessary duplication of efforts by the actors. Therefore, to avoid the perpetuation of this cycle it is necessary that supporting organisations interact. Such an initiative can provide a platform where ideas can be shared and integrated. Certainly, different organisations possess diverse ideological standpoints and practices with regard to urban agriculture (Battersby et al., 2015). This explains why there are variations in projects and project implementation across the city. However, this may be a good factor because it means that supporting actors may cover the needs of various types of urban farmers from diverse backgrounds. Moreover, while agendas may not always be reconciled, certain areas of cooperation may be identified and exploited. Mindful of the fact that such multi-stakeholder interaction has occurred, perhaps lacking is a continuity of such initiatives. Furthermore, urban farmers need to be actively involved and included in these multistakeholder dialogues. This may be the only way through which they can get a sense of ownership which improves the sustenance of such initiatives. Otherwise discussing problems urban farmers face in their absence may prove to be futile.

Another issue to note is the differences in objectives among the supporting actors and the urban farmers. Citing the aforementioned studies by Battersby \& Marshak (2013) and Tembo \& Louw (2013), it is clear that sharing the same aims among the supporting organisation and the urban farmer is crucial. Clearly, if the aims of the supporting actor are not in line with that of the beneficiary then that project is likely to fail (Tembo \& Louw, 2013). This is because there is a lack of participation, thereby reducing a sense of ownership of the initiative pursued. Nieman (2006) holds that developmental institutions need to ensure that there is improved participation in the projects 
implemented to ensure sustainability. Hence this needs to be applied in the context of urban agriculture as well.

Thirdly, while the work of NGOs in improving bridging, bonding and linking is highly commended, there is certainly still a need for improved self-organisation of urban farmers in Cape Town. Farmer associations do exist at provincial and national levels; however, there is the need for more farmer-driven groups at local levels. Such organisations are necessary because they respond to the experiences of the farmers in that particular locality, something which may not be reflected at higher levels of organisations. If such groups were to exist, they will probably be sustainable if they are self-organized by the farmers. This is not to say supporting actors cannot play a role in assisting them but there has to be a sense of grassroots formulation and participation to ensure that a sense of ownership is induced. Such initiatives will ensure that urban farmers are able to share ideas at localised levels and supporting actors may also facilitate the interaction of farmers across the city. Once there is a strong sense of unity among urban farmers, linking social capital may then be achievable, resulting in easier access to resources and facilitation of desired change from policymakers. Therefore, supporting actors need to be cognisant of the challenges urban farmers face in self-organisation as the first step towards identifying ways through which they can assist.

In sum, it is clear that there exists a rich foundation for realising the full potential of the urban agriculture sector in Cape Town. However, unlocking this potential is of utmost importance. This article contributes to the literature by arguing that the ubiquity of actors within the urban agriculture sector does not necessarily translate into the success of the activity. Cape Town's experience shows that it is neither a simple nor a linear process to achieve the desired results. Therefore, while the linkages between supporting actors need some refinement, urban farmers equally have a role to play. Accordingly, the article suggests that further empirical investigations are required which take into account the different types of urban farmers and actors in Cape Town. More case-specific inquiries as argued by Frayne et al. (2014) are crucial for policymakers to formulate appropriate responses to the urban farming communities in Cape Town. The social capital approach could be exploited in such investigations to ensure that the multidimensional interactions can be dissected and examined (Nieman, 2006) since they influence the state of urban agriculture in the metropolis.

\section{Disclosure statement}

No potential conflict of interest was reported by the author.

\section{ORCID}

Tinashe Paul Kanosvamhira http://orcid.org/oooo-0002-6745-1151 


\section{References}

Barr, K, 2017. Abalimi Bezekhaya: Improving food security with urban agriculture, resilience. 23 February 2017. http://www.resilience.org/stories/2017-0223/abalimi-bezekhaya-improving-food-security/ Accessed 5 December 2017.

Battersby, J \& Marshak, M, 2013. Growing communities: Integrating the social and economic benefits of urban agriculture in Cape Town. Urban Forum 24(4), 447461.

Battersby, J, Haysom, G, Tawodzera, G, McLachlan, M \& Crush, J, 2014. Food system and food security study for the City of Cape Town. https://www.researchgate.net/publication/305496094_Food_

System_and_Food_Security_Study_for_the_City_of_Cape_Town Accessed 5 May 2017.

Battersby, J, Haysom, G, Tawodzera, G \& Kroll, F, 2015. A study on current and future realities of urban food security in South Africa. Report for the South African Cities Network. https://www. researchgate.net/publication/284724728 Accessed 5 May 2017.

City of Cape Town (CoC), 2007. Urban agriculture policy for the city of Cape Town. Government Printer, Cape Town.

Dubbeling, M, de Zeeuw, H \& van Veenhuizen, R, 2010. Cities, poverty and food multistakeholder policy and planning in urban agriculture. Practical Action Publishing Ltd, Rugby.

Frayne, B, McCordic, C, Shilomboleni, H, 2014. Growing out of poverty: Does urban agriculture contribute to household food security in Southern African cities. Urban Forum 25(2), 177-189.

Haysom, G \& Battersby, J, 2016. Why urban agriculture isn't a panacea for Africa's food crisis. The Conversation, 15 April 2016. http://theconversation.com/whyurban-agriculture-isnt-a-panacea-for-africas-food-crisis-57680 Accessed 10 August 2017.

Haysom, G, Crush, J \& Caesar, M, 2017. The urban food system of Cape Town, South Africa. Hungry Cities Report NO. https://www.researchgate.net/publication/317348661 Accessed 10 August 2017.

Hoffmann, H, Fiege, K, Potzsch, C, Quive, S, Paolo, A, Tevera, D, Karriem, A, D’Aiuto, C, Baumann, M, Clausen, P \& Sparborth, D, 2016. Urban farming in Southern Africa - Improved food safety and income options for urban disadvantaged communities (UFiSAMo), Tropentag, September 18-21, 2016, Vienna, Austria.

Karaan, M \& Mohamed, N, 1998. The performance and support of foods gardens in some townships of the Cape Metropolitan area: An evaluation of Abalimi Bezekhaya. Development Southern Africa 15(1), 67-83.

Kirkland, D, 2008. Harvest of hope: A case study: The sustainable development of urban agriculture projects in Cape Town, South Africa. Master's thesis, University of Cape Town, South Africa.

Lee-Smith, D, 2011. Building resilient food systems -- Nairobi and environs food security, Agriculture and Livestock Forum. Mazingira Institute, Nairobi. 
http://www.fao.org/fileadmin/

templates/FCIT/workshops/Nairobi2011/presentations/3-Nairobi-Mazingira-DLeeSmith.pdf Accessed 5 May 2017.

Liou, T \& Chang, N, 2008. The applications of social capital theory in education. Hsiuping Journal of Humanities and Social Sciences 11, 99-122.

Maconachie, R, Binns, T \& Tengbe, P, 2012. Urban farming associations, youth and food security in post-war Freetown, Sierra Leone. Cities 29, 192-200.

Malan, N, 2015. Urban farmers and urban agriculture in Johannesburg: Responding to the food resilience strategy. Agrekon 54(2), 51-75.

Martin, A, Oudwater, N \& Meadows, K, 2000. Urban agriculture and the livelihoods of the poor in Southern Africa case studies from Cape Town and Pretoria, South Africa and Harare, Zimbabwe. Paper presented at the International Symposium - Urban Agriculture and Horticulture -the linkage with Urban Planning. Berlin 7-9 July 2000.

Megyesi, B, Kelemen, E \& Schermer, M, 2015. Social capital as a success factor for collective farmers marketing initiatives. International Journal of Sociology of Agriculture and Food 18(1), 89-103.

Minné, M, 2013. Urban agriculture in Cape Town \& the city of Cape Town urban agriculture policy 2007: To what extent the Policy contributes towards enabling the development of urban agriculture in the City Master's Thesis, University of Cape Town, South Africa.

Nieman, A, 2006. Social capital and social development. Social Work/Maatskaplike Werk 42(2), 163-172.

Olivier, D, 2015. The physical and social benefits of urban agriculture projects run by non-governmental organisations in Cape Town. Doctoral thesis, Stellenbosch University, South Africa.

Olivier, D \& Heinecken, L, 2017. The personal and social benefits of urban agriculture experienced by cultivators on the Cape Flats. Development Southern Africa 34(2), 168-181.

Putnam, R, 2000. Bowling alone: The collapse and revival of American community. New York: Simon \& Schuster.

Rabkin, N, 2013. Food for the future: Planning for urban agriculture in Cape Town's City bowl. Master's Thesis, University of Cape Town, South Africa.

Reuther, S \& Dewar, N, 2006. Competition for the use of public open space in lowincome urban areas: The economic potential of urban gardening in Khayelitsha, Cape Town. Development Southern Africa 23(1), 97-122.

Rogerson, C, 2010. Resetting the policy agenda for urban agriculture in South Africa. Journal of Public Administration 45(2), 373-383.

Saegert, S, Thompson, J \& Warren, M, 2001. Social capital and poor communities. Russell Sage Foundation: New York.

Schmidt, S, Magigi, W \& Godfrey, B, 2015. The organization of urban agriculture: Farmer associations and urbanisation in Tanzania. Cities 42, 153-159.

Small, J, 2007. The Siyazama community allotment garden association, Cape Town, South Africa. Urban Agriculture Magazine 16(February), 30-32. 
Soil for Life, (2017) About soil for life. https://www.soilforlife.co.za/about-us Accessed on 6 April 2017.

Sombalo, L, 2003. Urban livelihood strategies and urban agriculture activities in Khayelitsha communities, Western Cape. Master's Thesis, University of Pretoria; Pretoria.

Swanepoel, J, Van Niekerk, J \& D'Haese, L, 2017. The socio-economic profile of urban farming and non-farming households in The informal settlement area of the Cape Town metropole in South Africa. South African. Journal of Agricultural Extension 45(1), 131-140.

Szreter, S \& Woolcock, M, 2004. Health by association? Social capital, social theory, and the political economy of public health. International Journal of Epidemiology 33, $650-66$.

Tembo, R \& Louw, J, 2013. Conceptualising and implementing two community gardening projects on the Cape Flats, Cape Town. Development Southern Africa $30(2), 224-237$.

Thornton, A, 2008. Beyond the metropolis: Small town case studies of urban and periurban agriculture in South Africa. Urban Forum 19, 243-262.

Urban Agriculture and Food Security: Africa - Toronto Exchange Visit Report 14-22 June

2010. http://www.rooftops.ca/CMSImages/file/Urban\%20agriculture\%20and\%2ofood \%20security/Urban\%20Agriculture\%20Africa\%20Toronto\%20Exchange\%20\%20Visit\%2oreport.pdf Accessed 5 February 2018.

van der Merwe, L, 2003. Urban agriculture: Food for thought. Master's thesis, Stellenbosch University, South Africa.

van der Merwe, M, 2016. Food \& farming Campaign: An urgent plea to save Philippi Horticultural Area. Daily Maverick, Area, 28 FEB 2016. https://www.dailymaverick.co.za/article/2016-02-28-philippi-horticultural-areaan-urgent-plea-to-save-our-wetlands/\#.WoKUwqhsbcs Accessed 5 May 2017.

Visser, S, 2006. Concrete actions: Cape Town's urban agriculture assistance programme. Urban Agriculture Magazine 16(October), 48-50.

Voleníková, L \& Opršal, Z, 2016. The role of urban agriculture in household wellbeing: Case study of community-based urban agriculture in Ndola, Zambia. Development, Environment and Foresight 2(2), 80-90.

Wilbers, J, van Veenhuizen, R \& Castro, C, 2007. Strengthening urban producers' organisations. UA Magazine. http://www.ruaf.org/node/1082 Accessed 5 May 2017.

Woolcock, M, 2001. The place of social capital in understanding social and economic outcomes. ISUMA Canadian Journal of Policy Research 2(1), 11-17. 